\title{
Insulin resistance and significance of postprandial lipid profile in normoglycemic coronary artery disease
}

\author{
Mookambika RV ${ }^{1}$, Rajendiran ${ }^{2}$, Jayachandran ${ }^{3}$, Aruna ${ }^{4}$ \\ ${ }^{1}$ Dr Mookambika R V, Assistant Professor, Department of General Medicine, Sree Mookambika Institute of Medical \\ Sciences, Padanilam, Kulasekharam, Kanya Kumari District, Tamil Nadu.- 629161, ${ }^{2}$ Dr Rajendiran, Professor \& HOD, \\ Department of Cardiology, PSG Institute of Medical Sciences and Research, ${ }^{3}$ Dr K. Jayachandran, Professor \& HOD, \\ Department of General Medicine, PSG Institute of Medical Sciences and Research, ${ }^{4}$ Dr. Aruna, Professor Department of \\ Biochemistry, PSG Institute of Medical Sciences and Research, Off Avanashi Road, Peelamedu, Coimbatore-641 004, \\ Tamil Nadu, India.
}

Address for Correspondence: Dr Vishnu. G. Ashok, Assistant Professor, Department of Community Medicine, Sree Mookambika Institute of Medical Sciences Kulasekhram, Tamilnadu, India, Email: vishnusastha@gmail.com

\begin{abstract}
Background: Coronary artery disease is a continuum of a pathological process, in which the coronary arteries gradually thicken, harden and atherosclerotic plaques develop which further occludes the blood flow. The prevalence of coronary artery disease is rapidly rising in India. There are various risk factors of CAD which have been extensively studied, out of which Type-2 diabetes is an important etiopathogenic factor of accelerated CAD. Insulin resistance plays an important role in the pathogenesis of the development of type- 2 diabetes. Despite the clear relationship between type- 2 diabetes and CAD, the association of insulin resistance and CAD is more obscure in people without diabetes: Aims $\boldsymbol{\&}$ Objectives: To find the association between insulin resistance and Coronary artery disease, to evaluate the role of postprandial lipid profile and its relationship with development of CHD and the evaluation of apolipoproteins (a and b) on the same group. Subjects and Methods: Fifty patients of coronary artery disease admitted to ICCU/CCU of psg institute of medical sciences and research were studied. The cases of this present study were 50 non diabetic CAD patients and controls were selected based on age and sex matched non diabetic 'and non CAD patients who has to undergo similar set of investigations as cases to find out association of insulin resistance by using HOMA score and to find out the significance in abnormalities of postprandial lipid profile in these patients. Results: $92 \%$ of the cases had insulin resistance, $52 \%$ of the controls had normal HOMA score when compared to cases. Apolipoprotein b was significantly elevated in cases $(84 \%)$ than controls. All patients were normoglycemic. Serum triglycerides were significantly high in cases than controls in both fasting and postprandial states. Conclusion: Improving insulin sensitivity would offer substantial benefits by decreasing the morbidity, mortality, and economic burden associated with CAD especially in the country like India
\end{abstract}

Key words: Insulin Resistance, Coronary Artery Disease, Homa Score

\section{Introduction}

Coronary artery disease is a continuum of a pathological process, in which the coronary arteries gradually thicken, harden and atherosclerotic plaques develop which further occludes the blood flow [1]. This leads to clinical manifestations such as angina and acute coronary events resulting from disruption of plaques,

Manuscript received: $16^{\text {th }}$ December 2016

Reviewed: $26^{\text {th }}$ December 2016

Author Corrected: $04^{\text {th }}$ January 2017

Accepted for Publication: $11^{\text {th }}$ January 2017 such as acute coronary syndromes, myocardial infarction and death $[1,2]$.

The prevalence of CAD is rising rapidly in rural India. Lifestyle changes and aggressive control of risk factors are urgently needed to reverse this trend. Asian Indians have considerably higher prevalence of premature coronary artery disease and standardized mortality rates for $\mathrm{CAD}$ compared with Europeans. 
Within the Indian subcontinent, a dramatic increase in the prevalence of CAD has been predicted in the next 20 years due to rapid changes in demography and lifestyle consequent to economic development [3, 4].

There are various risk factors of CAD which have been extensively studied, out of which Type-2 diabetes is an important etiopathogenic factor of accelerated CAD. Insulin resistance plays an important role in the pathogenesis of the development of type- 2 diabetes. Elevated insulin levels and insulin resistance may be evident several years prior to the diagnosis of type- 2 diabetes. There are evidences supporting association of Insulin and CAD which indirectly reflects glucose intolerance, hypertension and dyslipidemia. However, the results from several studies are conflicting. Despite the clear relationship between type-2 diabetes and $\mathrm{CAD}$, the association of insulin resistance and CAD is more obscure in people without diabetes $[5,6]$.

It is well established that dysfunctional endothelium contributes to development and progression of atherosclerosis. Consequently, early detection and treatment of endothelial dysfunction may be an attractive strategy for preventing CAD. Unfortunately, established validated methods for assessment of endothelial dysfunction for chronic heart disease risk prediction in the clinical setting are not currently available. Current techniques to assess endothelial function are invasive, expensive, or suffer from lack of high sensitivity, specificity, reproducibility, or clinically defined cut-off values. Therefore, at this time, targeting established and modifiable risk factors for endothelial dysfunction and insulin resistance is the best primary strategy to prevent these conditions $[7,8]$.

Hypercholesterolemia and hyper triglyceridemia are considered the independent risk factors but most of the earlier studies in this area have considered only the fasting lipid profiles and lipoproteins. Recently it has been proposed that postprandial lipoproteins may be better indicators of deranged lipoprotein metabolism and hence of atherosclerosis and CHD. Postprandial hypertriglyceridemia (PHTG) and delayed triglyceride (TG) rich lipoprotein clearance have been found to impair endothelial function significantly either directly or by increasing superoxide anions.

It has also been reported that magnitude and duration of postprandial lipidemia is positively related to the pathogenesis and progression of CHD [9]. There is comparatively more transfer of cholesterol and cholesterol esters from HDL to LDL in postprandial state leading to their low levels and this along with higher triglycerides and VLDL levels are better indicators of coronary heart disease [10].

\section{Aims \& Objectives}

$>$ To find the association between insulin resistance and Coronary artery disease

$>$ To evaluate the role of postprandial lipid profile and its relationship with development of CHD

$>$ Evaluation of apolipoproteins (a and b) on the same group

\section{Materials and Methods}

Fifty patients of coronary artery disease admitted to ICCU/CCU of PSG Institute of medical sciences and research were studied. The cases of this present study were 50 non diabetic CAD patients and controls were selected based on age and sex matched non diabetic 'and non CAD patients who has to undergo similar set of investigations as cases to find out association of insulin resistance by using HOMA score [11] and to find out the significance in abnormalities of postprandial lipid profile in these patients. Patients with Acute coronary event and Non diabetics were selected as cases and the patients with Diabetics on insulin/ Oral hypoglycemic agents, Severe cardiac failure (classes 3 4), Renal hepatic, and other systemic diseases, Morbid obesity, History of malignancy and Previous h/o dyslipidemia were excluded. The selected patients were studied in detail with history and physical examination. Complete blood picture, Urine analysis, Renal function tests fasting Blood sugar and postprandial blood sugar, glycosylated haemoglobin, Fasting and post prandial lipid profile. Apolipoprotein $\mathrm{a}$ and $\mathrm{b}$ Fasting insulin levels, Chest x-ray, Electrocardiogram Echocardiogram and Coronary Angiography were done in patients. The estimation of Insulin resistance by HOMA score = fasting insulin $(\mathrm{Mu} / \mathrm{L}) \times$ fasting glucose $(\mathrm{mmol} / \mathrm{L}) / 22.5$. The study Parameters entered in Microsoft Excel spread sheet and statistically analysed using Chi-square and Fisher Exact test to find the significance of proportion of incidence of insulin between various levels of study parameters namely BMI, Age, abnormal lipid profile and complications etc. and Student $t$ test to find the significance of mean levels of lab parameters between the presence and absence of insulin resistance. 


\section{Results}

Among cases $70 \%$ of patients were males and $30 \%$ were females, Among controls $66 \%$ patient were males and $34 \%$ were females $.10 \%$ of the CAD patients and $9 \%$ of the controls had habit of consuming smoking and alcohol. $72 \%$ of the cases and $68 \%$ of the control are obese. $92 \%$ of the cases had insulin resistance, $52 \%$ of the controls had normal HOMA score when compared to cases. Apolipoprotein b was significantly elevated in cases (84\%) than controls. All patients were normoglycemic. Serum triglycerides were significantly high in cases than controls in both fasting and postprandial states.HDL and Total cholesterol was unchanged both in fasting and postprandial state LDL cholesterol was found to be mildly increased in patients but not significantly as fasting level. TG/HDL RATIO was found to be $>4$ in cases with insulin resistance when compared to those without insulin resistance. TC/HDL RATIO was found to be $>3.5: 1$ in high in cases \& controls with Insulin resistance (72\%, 43.2\% respectively) when compared to patients without insulin resistance. Post prandial triglycerides where high when compared to fasting levels among cases when compared to controls. Percentage of postprandial hypertriglyceridemia was much higher in cases when compared to controls. Significant association of Obesity \& Insulin resistance in cases and controls (Table 1\& 2)

Table-1: Relationship between Insulin Resistance and BMI Fishers exact test- Cases

\begin{tabular}{|c|c|c|c|c|c|c|c|}
\hline & \multicolumn{2}{|c|}{ Normal } & \multicolumn{2}{c|}{ Obese } & \multicolumn{2}{c|}{ Total } & P value \\
\cline { 2 - 7 } & No & \% & No & \% & No & \% & 0.041* \\
\hline Normal & 4 & 40.0 & 4 & 10.0 & 8 & 16.0 \\
\hline Abnormal & 6 & 60.0 & 36 & 90.0 & 42 & 84.0 \\
\hline Total & 100 & 100.0 & 40 & 100.0 & 50 & 100.0 & \\
\hline
\end{tabular}

Table-2: Relationship between Insulin Resistance and BMI Fishers exact test- Controls

\begin{tabular}{|c|c|c|c|c|c|c|c|}
\hline \multirow{2}{*}{} & \multicolumn{2}{|c|}{ Normal } & \multicolumn{2}{c|}{ Obese } & \multicolumn{2}{c|}{ Total } & P value \\
\cline { 2 - 7 } & No & \% & No & \% & No & \% & 0.002* \\
\hline Normal & 22 & 68.8 & 4 & 22.2 & 26 & 52.0 \\
\hline Abnormal & 10 & 31.2 & 14 & 77.8 & 24 & 48.0 \\
\hline Total & 16 & 100.0 & 34 & 100.0 & 50 & 100.0 & \\
\hline
\end{tabular}

\section{Discussion}

Coronary artery disease (CAD) is continuums of a pathological process, in which the coronary arteries gradually thicken \& harden and atherosclerotic plaques develop that further occlude blood flow. This leads to clinical manifestations such as angina and acute coronary events such as acute coronary syndromes, myocardial infarction and death, due to the disruption of plaques.

Coronary artery disease is the leading cause of death in India and is also the leading cause of death worldwide. It was previously thought to affect primarily the population of developed countries. CAD now leads to more death and disability in developing countries such as India. CAD affects people at younger ages in developing countries compared to developed countries, thereby having a greater economic impact. Effective screening, evaluation and management strategies for coronary artery disease are well established in developed countries, but these strategies are not fully implemented in India. For the development \& implementation of such strategies identifying the risk factors is an important initial step.

An effort has been made to recognize insulin resistance in non-diabetic CAD patients which is a simple and non-invasive practical tool. It requires only a single sample assayed for Insulin and glucose and can be calculated by HOMA score [11].

There was significant insulin resistance (IR) ( 92\%) among cases. This is similar to a study done by Bertoluci et al [12] from Brazil which showed $82.6 \%$ of CAD patients had insulin resistance when compared to the controls/non CAD group. Another American study by David et al [13] showed that IR was responsible (96\%) for $46.8 \%, 6.2 \%$ and $12.5 \%$ of the annual CHD events in diabetics, non-diabetics and total US 
population respectively. Yet another study by E. Devici et al [14] which compared Insulin resistance among normoglycemic patients with CAD revealed significant association of IR. Metabolic syndrome was similar in both the control and cases and thus HOMA IR values may provide more sensitive information than the Metabolic syndrome definitions about the association of IR and CAD in normoglycemic patients. Like the above study quoted, there was significant association of obesity and Insulin Resistance in our study which was $84 \%$ In the CAD group and $77.8 \%$ in the non CAD group. Approximately $50 \%$ of patients with essential hypertension, both treated and untreated, appear to be insulin resistant based on the study by Roopa et al [15].

Significance of the postprandial lipid profile in patients with CAD is a new and emerging study which has only limited references $\&$ is not practiced routinely day to day clinical setup. In this study Serum triglycerides were significantly high in cases than controls in both fasting and postprandial states. Total cholesterol was unchanged both in fasting and postprandial state. HDL cholesterol was found to be decreased significantly in fasting state, but LDL cholesterol was found to be mildly increased. A study by Vijay et al[16] done in Haryana showed significant elevation of Serum TG, total cholesterol and VLDL - cholesterol in patients than controls in both fasting and postprandial states $(p<0.001)$ and HDL-cholesterol was found to be decreased significantly in fed state only $(\mathrm{p}<0.05)$.

It concluded that there is comparatively more transfer of cholesterol and cholesterol esters from HDL to LDL in postprandial state leading to their low levels and this along with higher triglycerides and VLDL levels are better indicators of coronary heart disease. Apoprotein $b$ was significantly higher in CAD group when compared to controls which is similar to a study by Bertsch RA et al [17] which showed that these pro-atherogenic lipoproteins were strong predictors of CAD when compared to the non HDL cholesterol. In those controls (4 patients) in whom Apo B was elevated there was also Insulin Resistant.

Among them, 2 patients were hypertensive and their ECHO and ECG showed features of left ventricular hypertrophy. Other two were obese without pre morbidities and had non specific ST-T changes in ECG with a normal ECHO study. Apo B, TG/HDLc ratio and $\mathrm{Tc} / \mathrm{HDL}$ ratio were significantly higher among patients with insulin resistance

\section{Conclusion}

There is insulin resistance in patients with coronary artery disease and also among non diabetic patient who are obese. Apolipoprotein b levels where significantly raised in $\mathrm{CAD}$ patients. Serum triglycerides were significantly high in cases than controls in both fasting and postprandial states. Percentage of postprandial hypertriglyceridemia was much higher in cases when compared to controls. Fed state did not alter the total cholesterol/ LDL/HDL significantly. Patients with IR had high TGL/HDLc, TC/HDLc and Apo B values. Fasting Insulin and Insulin resistance (HOMA SCORE) can be included as one of the panel of investigations to assess the risk factor of CAD among nondiabetic population. Earlier identification of these patients would help to intervene and improve the quality of life. Improving insulin sensitivity would offer substantial benefits by decreasing the morbidity, mortality, and economic burden associated with $\mathrm{CAD}$, especially in the country like India.

\section{Funding: Nil, Conflict of interest: None. Permission of IRB: Yes}

\section{References}

1. Joseph J, Shamburek RD, Cochran EK, Gorden P, Brown RJ. Lipid regulation in lipodystrophy versus the obesity-associated metabolic syndrome: the dissociation of HDL-C and triglycerides. J Clin Endocrinol Metab. 2014 Sep;99(9):E1676-80. doi: 10.1210/jc.2014-1878. Epub 2014 Jun 13.

2. Reaven GM, Lerner RL, Stern MP, Farquhar JW. Role of insulin in endogenous hypertriglyceridemia. J Clin Invest. 1967 Nov;46(11):1756-67.

3. Howard G, O'Leary DH, Zaccaro D, Haffner S, Rewers M, Hamman R, Selby JV, Saad MF, Savage P, Bergman R. Insulin sensitivity and atherosclerosis. The Insulin Resistance Atherosclerosis Study (IRAS) Investigators. Circulation. 1996 May 15;93(10):180917.

4. Miller GJ, Miller NE. Plasma-high-densitylipoprotein concentration and development of ischaemic heart-disease. Lancet. 1975 Jan 4;1(7897):16-9.

5. Welborn TA, Breckenridge A, Rubinstein AH, Dollery CT, Fraser TR. Serum-insulin in essential hypertension and in peripheral vascular disease. Lancet. 1966 Jun 18;1(7451):1336-7. 
6. Juhan-Vague I, Alessi MC, Vague P. Increased plasma plasminogen activator inhibitor 1 levels. A possible link between insulin resistance and atherothrombosis. Diabetologia. 1991 Jul;34(7):457-62.

7. Kahn BB, Flier JS. Obesity and insulin resistance. J Clin Invest. 2000 Aug;106(4):473-81.

8. Gavrilova O, Marcus-Samuels B, Graham D, et al. Surgical implantation of adipose tissue reverses diabetes in lipoatrophic mice. Journal of Clinical Investigation. 2000;105(3):271-278.

9. Klannemark M, Orho M, Langin D, Laurell H, Holm C, Reynisdottir S, Arner P, Groop L. The putative role of the hormone-sensitive lipase gene in the pathogenesis of Type II diabetes mellitus and abdominal obesity. Diabetologia. 1998 Dec;41(12):1516-22.

10. Babirak SP, Brown BG, Brunzell JD. Familial combined hyperlipidemia and abnormal lipoprotein lipase. Arterioscler Thromb. 1992 Oct;12(10):1176-83.

11. Matthews DR, Hosker JP, Rudenski AS, Naylor BA, Treacher DF, Turner RC. Homeostasis model assessment: insulin resistance and beta-cell function from fasting plasma glucose and insulin concentrations in man. Diabetologia. 1985 Jul;28(7):412-9.

12. Bertoluci MC, Pimazoni-Netto A, Pires AC, Pesaro AE, Schaan BD, Caramelli B, Polanczyk CA, Júnior CV, Gualandro DM, Malerbi DA, Moriguchi E, Borelli FA, Salles JE, Júnior JM, Rohde LE, Canani LH, Cesar LA, Tambascia M, Zanella MT, Gus M, Scheffel RS, Dos Santos RD. Diabetes and cardiovascular disease: from evidence to clinical practice - position statement
2014 of Brazilian Diabetes Society. Diabetol Metab Syndr. 2014 May 20;6:58. doi: 10.1186/1758-5996-658. eCollection 2014.

13. Hadaegh F, Derakhshan A, Mozaffary A, Hasheminia M, Khalili D, Azizi F. Twelve-Year Cardiovascular and Mortality Risk in Relation to Smoking Habits in Type 2 Diabetic and Non-Diabetic Men: Tehran Lipid and Glucose Study. PLoS One. 2016 Mar 1;11(3):e0149780. doi: 10.1371/journal.pone.0149780. eCollection 2016.

14. Deveci E, Yesil M, Akinci B, Yesil S, Postaci N, Arikan E, Koseoglu M. Evaluation of insulin resistance in normoglycemic patients with coronary artery disease. Clin Cardiol. 2009 Jan;32(1):32-6. doi: 10.1002/clc.20379.

15. Roopa AN ,Reddy KSS ,Chandrasekhara P, Umabai KR .Study of microalbuminuria and insulin resistance in patients with essential hypertension and metabolic syndrome and its relationship to target organ damage.J Med Sci Health 2015;1(3):5-9

16.Shankar V, Kaur Harnam, Dahiya K.Comparison of Fasting and Post prandial Lipoid profile in patients of coronary heart disease. Bombay Hospital Journal.2008;50(3).

17. Bertsch RA, Merchant MA. Study of the Use of Lipid Panels as a Marker of Insulin Resistance to Determine Cardiovascular Risk. The Permanente Journal. 2015;19(4):4-10.

\section{How to cite this article?}

Mookambika RV, Rajendiran, Jayachandran, Aruna. Insulin resistance and significance of postprandial lipid profile in normoglycemic coronary artery disease. Int J Med Res Rev 2017;5(01):15-19.doi:10.17511/ijmrr. 2017.i01.02 